\title{
EVALUATION OF THE SAWMILLING WASTAGE OF SAWMILLS IN WESTERN PROVINCE OF SRI LANKA
}

\author{
P Saman Weerawansa ${ }^{1}$, H S Amarasekera ${ }^{1}$ and M N Attygalla ${ }^{2}$ \\ ${ }^{1}$ Department of Forestry \& Environmental Science, University of Sri Jayewardenepura \\ ${ }^{2}$ State Timber Corporation, Kaldemulla
}

The main objective of this study is to find the amount of sawmilling wastage of popular sawn timber species used in the sawmills situated in the Western Province of Sri Lanka.

Fifteen sawmills were selected out of 345 registered sawmills in the western province by using a random sampling method. The selected sawmills represent all types of sawmill machinery available in Sri Lanka, (Horizontal band saws, vertical band saws, circular saws and frame saws). Twelve common timber species were also selected. One hundred and sixty five logs representing the selected twelve species were measured and sawn at the selected fifteen sawmills. For each log, length and under bark mid girth were measured to calculate $\log$ volume. Sawn timber produced from each log was also measured and volume was calculated. Percentage loss in conversion was calculated.

The percentage loss in conversion of sawmills in Western Province is $55.7 \%$. Percentage loss in conversion varies with the type of sawing machine. The most wasteful machine is the inserted tooth circular saw (percentage loss in conversion is $(54.1 \%$ ). Percentage loss in conversion values are respectively lower in circular saw $(53.2 \%)$, vertical band saw $(47.8 \%)$, horizontal band saw (44.4\%) and horizontal frame saw (42.4\%).

Percentage loss in conversion of the selected 12 timber species varied; jak when sawn using a circular saw gave the highest percentage loss in conversion $(60.8 \%)$, followed by Albizia when sawn using inserted tooth circular saw (59.2\%). Mahogany when sawn using a horizontal band saw, showed the lowest percentage loss in conversion (33.6\%). Saw gauge does not significantly affect the loss in conversion.

The value of the sawmill machines is Rs.250,000/ and up. The value of the raw materials shows wide variation: $\log$ price Rs.60 per cu.ft.(rubber) to Rs.550 per Cu.ft.(Teak). Most sawmills cannot work throughout the year due to lack of raw materials and financial problems. Generally workers are hired on daily paid basis and their salaries vary from Rs. 150 to Rs. 350 per day which depends on the timber species, machinery used and end products (Rs. 25 per.cu.ft. to Rs. 40 per cu.ft.).

Major causes for wastage can be attributed to technological problems such as adopting a through and through sawing method to produce the widest boards, rather than sawing to produce a mix of sizes, use of bad sawing practices such as poor log alignment and improper log turning, use of low gauge wide diameter saws to cut small diameter logs which could be converted by small diameter high gauge saws, inefficient and inadequate saw maintenance (saw doctoring) and use of out-dated machinery. Improper bucking practices at the logging sites, log defects and inefficient sawmill management are the other factors which cause higher wastage.

Proceedings of the Third Annual Forestry Symposium 1997, of the Department of Forestry and Environmental Science, University of Sri Jayewardenepura, Sri Lanka 